\title{
Urban Places as Aesthetic Phenomena: Framework for a Place-Based Ontology of Urban Lifeworld
}

\author{
Vesa Vihanninjoki ${ }^{1}$ (i)
}

Published online: 3 January 2019

(c) The Author(s) 2019

\begin{abstract}
Urban places are of central significance for cities both as built structures and as centers of everyday life. Due to the emergence of various design-led place-making policies and practices, "urban place" has largely become a marketed and branded product. Aesthetics plays a major role in this project of place-making, and the related interpretation of "commodified aesthetics of place" emphasizes certain experiential and qualitative place-attributes—such as authenticity—despite apparent conceptual confusions and controversies. A thorough reconsideration of central place-concepts is required to shed light on this problematic sphere. This article provides an alternative reading of urban places and the related aesthetic dimensions, based primarily on a Heideggerian account of human existence as placed being in the world. Such an approach emphasizes the decisive difference between an object-based and a contextual interpretation of place, providing also a framework for understanding the aesthetics of place and its fundamental lifeworld-constituting role anew.
\end{abstract}

Keywords Environmental aesthetics · Place · Place-making · Urban environment · Urban lifeworld · Philosophy of the city

\section{Introduction}

Places are very significant for the well-being and flourishing of both local urban communities and entire urbanized societies, as well as for the planning, construction and maintenance of cities as material environments. Places also function as nodes that connect the social and the material in urban contexts; the emphasis on urban places means thus a focus on understanding and managing urbanism and the urban life-form itself, as a whole.

Places and the complex, long-lasting processes of deliberately creating them - that is, place-making-also often lie at the core of different urban policies that aim at governing both social and physical dimensions of the city. "Place-talk" in part defines the context for operations of urban and social planning, urban design, as well as architecture. The notions of place and place-making are also central to connecting global-level objectives and ideals (such as ecological and socio-cultural sustainability) with local-level strategies and actions (often related to more tangible economic issues,

* Vesa Vihanninjoki

vesa.vihanninjoki@helsinki.fi

1 Department of Philosophy, History and Art Studies, University of Helsinki, Helsinki, Finland such as efficient resource usage), and the interconnections between the discourses of place and sustainability in particular, are very strong (Lister 2012, p. 52).

It does seem that pursuing or enhancing the sustainability of contemporary urban life-form by creating better and more meaningful places has become a sort of hegemonic project. Place-making is indeed "a topic with which it seems impossible to disagree"-it has become an irresistible buzzword, like "sustainable development", "urban renaissance" or "sustainable communities" (Palermo and Ponzini 2015, p. 2). The meanings of such general level notions are, however, rather ambiguous, so that there is always plenty of room for varying interpretations. This might become a real problem, since if the central notions of place-making can mean practically anything, they end up meaning nothing: the notions lose their substantiality and the related authority, if too many possible alternative courses of action can be legitimized by references to them. For example, Dovey (2016, pp. 259-260, emphases added) has criticized the overly loose use of place-related concepts, stating that "place is a nebulous and somewhat dangerous concept, which can be used to argue for more buildings or less of them", for which reason "the discourses of place and place-making are thoroughly interwoven with practices that can also be described as place destruction". 
Place-related conceptual obscurities have their roots, to some extent, in a relatively recent development that has remarkably shifted the focus of place-discourse from static and essentialist conceptions of place to dynamic and more open interpretations. This has do to with the fact that places as phenomena and place-concepts nowadays have notable economic connotations: particularly in the context of designoriented urban planning, place-talk often follows the logic of the globalized and mobility-oriented financial world-that is, the logic of marketing and branding (Kovács and Musterd 2013, pp. 99-101). Hence it is important to note that the dynamism characteristic of the global financial world has not completely undermined the significance of places and place-talk, but merely altered the uses and meanings of central place-related concepts.

The fact that places and their prominent features, such as the sense of place, have become valuable commoditieskinds of objects of trade-has influenced the discourses of place and place-making quite remarkably, bolstering particularly such interpretations that reduce the language of place to "profitable slogans-slippery conceptions of place identity and urban character that fit easily into neoliberal ideology" (Dovey 2016, p. 257). This kind of evolution in popular place-talk seems also to have notable bearings on the relation between places and aesthetics, so that specific experiential and thus qualitative features of places are emphasized. For example, "genuineness" and "authenticity" are nowadays regarded as important components of the quality of place (Palermo and Ponzini 2015), no matter how ambiguous and ill-defined these attributes may be.

Authenticity, in particular, has become a desirable placefeature that is sought through deliberate urban design, in that authentic places are largely conceived as generally available "design-artifacts". This has proven to be a rather problematic endeavor, for as Paul Knox (2005, p. 4) has pointed out, the "invented traditions, sanitized and simplified symbolism, and commercialized heritage" characteristic of professionally designed and commercially constructed urban places seems to remarkably contribute to the process of places becoming ever more convergent - and thus presumably less authentic.

In general, "urban place" has thus become a marketed and branded product that is supposedly brought about through various place-making policies and related urban design practices. The related aesthetics of place, in turn, has to do with certain experiential attributes that can be observed, invented and attached to places "from above"- that is, from the "off-grass roots perspective" of policymakers and urban designers. Such an interpretation of places and the related aesthetic dimensions can be labeled as the "commodification of places", which by and large relies on a one-dimensional and overly simplifying conception of "commodified aesthetics of place".
The notions of "place" and "aesthetics", however, involve complexities that may seriously hinder such a design-led project of place-making. Basically, the supposedly static and thus governable objectified places are essentially the outcome of reductive theorizing on the inexhaustible manifoldness and equivocality inherent in the urban sphere. Additionally, the aesthetic features typically associated with these kinds of urban places represent a very limited sample of aesthetic phenomena, and a rather narrow-minded understanding of aesthetics in general: the discourses of place-making tend to neglect the essential diversity and pluralism inherent in aesthetic valuation and, above all, the fundamental role that aesthetics has in the constitution of the everyday urban lifeworld. At worst, the objectified places are regarded as aesthetic objects, or as autonomous and self-referential artworks-all of which are ill-fitting metaphors for an environment in which real people live their day-to-day lives.

To shed light on this rather problematic sphere, it is necessary to open up and critically examine the philosophical foundations underlying the common conceptions of place, place-making, and the aesthetics of place. A thorough reconsideration of places, aesthetics ${ }^{1}$, and the aesthetics of places is indeed in order, if the increasingly influential project of place-making is to be founded on a more solid ground. This article provides an alternative reading of urban places and the related aesthetic dimensions, based primarily on a Heideggerian account of human existence as placed being in the world. Such an approach emphasizes the decisive difference between an object-based and a contextual interpretation of place, providing also a framework for understanding the aesthetics of place and its fundamental lifeworld-constituting role anew.

\section{Objectified and Contextual Places}

As an introduction to the theme, let us begin with a lengthy quotation from Edward Relph's classic study Place and Placelessness (originally published in 1976), which has had a remarkable influence on the academic discourse of place for many decades, inspiring already several generations of researchers. Indeed, many important definitions, as well as certain unexplicated assumptions, made by Relph have also remained symptomatic in the later tradition of

\footnotetext{
1 Throughout the text, the term "aesthetics" refers to the domain of aesthetically relevant phenomena, not to aesthetics as a discipline of philosophy. The task of defining "aesthetics" (what, exactly, counts as aesthetically relevant phenomena) lies, however, outside the scope of the article at hand. For the current purposes it suffices to say that there is indeed a plethora of potential definitions available, and that the focus here is on clarifying apparent conceptual confusions and controversies.
} 
human geography and the related fields of place-research. I do not, however, intend to claim that all human geography since Relph's work relies on exactly the same theoretical presuppositions and thus deterministically follow the path marked by this classic; there surely are differing views and alternative options. That said, many of the ideas that have been - and often still are-central to the academic tradition of place-research can be found here:

Places are [...] incorporated into the intentional structures of all human consciousness and experience. Intentionality recognizes that all consciousness is consciousness of something. [...] The objects and features of the world are experienced in their meaning and they cannot be separated from those meanings. [...] Places are the contexts or backgrounds for intentionally defined objects or groups of objects or events, or they can be objects of intention in their own right. [...] The basic meaning of place, its essence, does not [...] come from locations, nor from the trivial functions that places serve, nor from the community that occupies it, nor from superficial and mundane experiences - though these are all common and perhaps necessary aspects of places. The essence of places lies in the largely unselfconscious intentionality that defines places as profound centres of human existence. (Relph 2016, pp. 42-43, emphases altered.)

For Relph, the intentionality of human consciousness and experience is thus crucial in defining the essence of place: places seem to have a very central role in giving structure to our lifeworld, either as objects of intention or as contextual backgrounds for such objects and events. However, the concepts of "intention" and especially "intentionality" have a somewhat ambiguous meaning here: on the one hand, intentionality has to do with consciousness, and it is in a way assimilated to the directedness of consciousness ("all consciousness is consciousness of something"); on the other hand, it can be treated as a more general feature of human experience and existence, hence transcending the dimension of mere consciousness. It is important to note that there is not anything wrong with the term "intentionality" in itself; for example, Don Ihde (1979, pp. 116-117; see also Verbeek 2005, pp. 76-83) uses the term "existential intentionality" in order to capture the nature of this latter type of sociomaterial intentionality that describes human existence on a more general level. These two dimensions of places' intentionality become, nevertheless, intertwined in Relph's analysis with detrimental implications for understanding place as a phenomenon.

More specifically, the duality with regard to the meaning of intentionality seems to correspond with the duality concerning of the notion "place" itself-that is, the fact that places appear either as objects of intention, or as contextual backgrounds for such objects, depending on the chosen point of view. The problem here is that Relph applies a kind of "consciousness-based model of intentionality" also to places rather straightforwardly. In the usual case, a particular object —or a particular, relatively easily distinguishable feature of the world-may (or may not) be in the focal point of our conscious experience; the question about which particular object or feature we currently focus on is a matter of contingency, and the answer depends mainly on our (momentary) intentions and interests. With place, however, the situation is different for there is, in fact, one major inconsistency - at least if we also use exactly the same notion of "place" when referring to the background or context of different objects and events, as Relph indeed does.

The background or context against which various objects or events are experienced cannot, strictly speaking, itself become an object of experience. This is due to the very nature of background or context, and the fundamental fact that the background's way of being is not that of an object, but something rather different. If the background is supposedly moved to the foreground - to the focus of experienceit ceases to be a background, and thus in a sense is not the same "thing" anymore. With regard to places, if a particular place that initially serves as a background for certain objects and events of interest to us supposedly becomes an object of experience itself, as we shift our focus onto it, the place in question "is" not the same as it used to be just a moment ago: as an object it "is" something quite different from a background or from a context. The remarkable difference between these two "modes" of places' being will be emphasized by introducing the corresponding concepts "place-asobject" and "place-as-context", which eventually point to a fundamental distinction that the traditional discourses of place may not properly recognize.

More precisely, when we begin to pay attention to the background of our "usual" experience, we actively (but not necessarily consciously) do construct a new object of experience in a very similar way to when we are dealing with more "conventional" objects of experience; however, we simultaneously gain a new experiential background or context against which this "objectified place" is drawn-a background which is a place once again, but in a different sense from the objectified one. To be sure, the relationships between the "old" and "new" background-like places depend on many factors, and the occurring changes do not have to be, and most likely are not, all-encompassing. For example, if we (deliberately or not) happen to focus on the physical or geographical location of the experiential whole - that is, the location of the bodily experience as an event, thus including the background-the exact location of our experience itself naturally does not alter. However, the usually hidden or tacit meaning-structures that constitute the way we understand "location" (i.e. our theoretical knowledge of 
geography, perhaps certain branches of mathematics like geometry, etc. as well as our everyday knowledge of our habitat, and operating and moving around within it) become a more prominent part of the experiential background than before, though they still are not explicated at once. Some other aspects of our context of experience, in turn, give way to these diverse location-related referential meanings, fading in the periphery of our experiential horizon.

As it has now become clear, place in this latter sense-as a background or context-has little to do with mere location or spatially locatable things. It is more about the fundamental features of human experience and existence, about the non-object-like structures and relations of meanings that always and continuously condition our being in the world. This being said, one might ask whether it is necessary or even appropriate to use the notion of "place" at all when referring to the phenomenon of background or context. In other words: why one should call the background or context a "place", if some essential nuances or connotations usually associated with place (e.g. those related to geographical location) are missing?

\section{Placedness as the Human Condition}

The primary reason for sticking to the concept "place" has to do with a certain particular conception of the human experience and existence. In a similar way that the different branches of existential phenomenology emphasize the embodiedness or the situatedness as the general condition of human existence, a more recent approach called "philosophical topography" (see Malpas 1999, 2006, 2012) acknowledges the placedness of the human existence-the fact of constantly being placed, the fact that the human existence is by definition being in a place - as the starting point. Such a change in the applied conceptual framework might be best described as a shift in focus: where the term "embodiedness" highlights the concrete physicality and the consequent physical preconditions and possible limitations that frame human existence, and where "situatedness" brings forth the abstract, temporally and historically defined systems of meaning (the "hermeneutical horizon") among which we find ourselves, "placedness" combines these two approaches.

In short, placedness as the human condition states that being human is always about being placed in a physical world that exceeds the being of any particular human being, and that is already understood in a primordial way before any conscious or intentional action or interpretation can take place. In other words, our physical bodies always have their place, according to which we orientate ourselves in an already meaningful world that "is" there regardless of us. Hence, our understanding of this world is in a very fundamental way bound to our place, which eventually comprises an essential part of what we are-of our possibilities and obligations in this very world.

Such understanding of placedness relies on the Heideggerian account of human existence as Dasein-outlined in Being and Time (published originally in 1927). In fact, the term Dasein itself rather straightforwardly names being placed and being-in-the-world as the fundamental human condition. As Abraham Olivier (2017, p. 13) points out: “'Da-sein', literally translated as 'there-being', basically means to be placed, to be involved in the world. In this fundamental sense, place refers to world and our being placed in it."

What is most important here, is the certain conception of place that Heidegger introduces (though perhaps not in an explicit or even very coherent way; see Malpas 2006, pp. 28-32). The nature or character of the place in which Dasein's being-in-the-world always "actualizes" is not that of an object or a group or a constellation of objects, but that of a background or a context. Two distinct remarks follow: first, being placed means being surrounded or embedded in a setting rather than being surrounded by objects; second, the being of this kind of place itself cannot be understood as the being of any kind of object-like container which could, in principle, be observed from outside. Such objectifications of Dasein's being in a place are not, however, in a sense impossible-perhaps quite the contrary, they have been and still are rather common-but they are always secondary, and they basically neglect or even misunderstand the fundamental nature of placedness as the human condition.

The lesson here is that the notion of place that Heidegger operates with simply cannot be reduced completely to either an object-based conception of place, or to the realm of object-based ontology. The contextual place is thus something fundamentally different from objectual place, in that the context's way of being is essentially connected to Dasein's existence as being placed in the world ("being-ina-place-in-the-world"). Similarly as the world "is" not anything separate from worldly humans ("world' is not a way of characterizing those entities which Dasein essentially is not; it is rather a characteristic of Dasein itself", Heidegger 1978, p. 92), the contextual place "is" not something that can be grasped from an objective point of view-that is, standing outside the human-place or human-world relationships. These relationships, in turn, are not transparent to our conscious inquiries, so that we could objectify them as the object-like focus of our intentional examinations. One could even say that similarly as the "world worlds" (Heidegger 2002a, p. 23), the place-as-context "contexts"- but it does not exist as a separate object-like entity. This is why, as stated earlier, the context against which objects or events are experienced simply cannot itself become an identifiable object of experience. 
Without getting involved in the complexities of Heideggerian existential phenomenology in depth, certain basic conceptual distinctions are yet needed in order to understand more profoundly the apparent shortcomings inherent in Relph's account of places-that is, the shortcomings in identifying the two distinct dimensions of places' intentionality. What follows is a brief examination of "equipment" and especially "equipmentality"the most characteristic features of the equipment's way of being-for these are closely related to the essence of non-object-like places and the related existential intentionality.

According to Heidegger, the way of being of an equipmental entity ("a piece of equipment" or "a tool") is not that of an individual object which may be inspected and comprehensively grasped in itself, but rather is that of a referential being. A referential being is essentially a part of a larger totality that exceeds its own being (as an "objectified item"). As a referential being, a tool can never, in a sense, exist on its own, but it gains its meaning and assignmental relevance from the equipmental whole; for example, a pen is essentially related to the functional entirety of ink-stand, ink, paper, blotting pad, table, lamp, furniture, windows, doors, room, etc. (Heidegger 1978, p. 97).

That the pieces of equipment always gain their "essence" from the equipmental whole, is in correspondence with the fact that under "usual" circumstances we do not encounter tools themselves, as they are not "visible" to us. Tools are not our primary concern, and not even the entirety of work at hand, but rather the everyday dealings and involvements of our lives: we are not primarily "interested" in the equipment, or even the use of such equipment, but the outcomes that the use of the equipment give rise to-and also the further possibilities that the concrete outcomes merely open up to us. In short, equipment is always and necessarily "something in-order-to", where the "in-order-to" stands for a "practical directness" that is inherent in all equipment (Heidegger 1978, pp. 97-100, 1982, pp. 292-293.)

It must be yet acknowledged that the "arc" from the equipment and its use to the outcomes and the related possibilities of being and acting in the world is not transparent to us, in that we would have some kind of "mental image" of the "in-order-to" transition in front of us (Heidegger 1982, p. 293). Understanding the "directness" of such functionality is not conscious but essentially practical by nature, and the "in-order-to" functionality relation thus constitutes an "existential intentional arc" that is fundamentally different from, and irreducible to, the intentionality arc of consciousness, spanning from the experiencing subject to the experienced object (see Ihde 1979, pp. 116-117).

\section{Contextual Places and the Constitution of Lifeworld}

Such an analysis of equipment and equipmentality is also likely to turn out to be very helpful in understanding the backgroundness or contextness of places. In general, our being in the world, as realized through being in a place, implies a certain placement in an equipmental environment, and eventually the state of being familiar with different things in our environment (Olivier 2017, p. 13). Furthermore, our closest and most familiar everyday environments-understood as the backgrounds or contexts of our day-to-day life-do have much in common with equipmental totalities, consisting of numerous and complex "inorder-to" structures that usually conceal themselves from us (Haapala 2017, pp. 173-174).

Much of our being-in-the-world does indeed consist of familiarity and of things that we are used to, so that our everyday context is usually taken for granted, without questioning its givenness (Haapala 2005, p. 49; see also Dovey 1999, p. 2). This is because our socio-materially constituted lifeworld is opaque in the sense that it does not reveal the existential intentionalities behind its unquestionable presence; in a similar way, our typical day-to-day environment presents itself as the "normal" context for living, but it does not explicitly show exactly what constitutes its normalcy.

It must yet be recognized that even the most familiar environments do sometimes reveal themselves and become visible; at times they even draw our attention and demand measures. Thus our environment and the places within it sometimes can and do become objectified-they are treated as object-like entities - even though such objectifications are necessarily "partial", in that they may never be comprehensive and they systematically disregard certain aspects or dimensions of our being-in-the-world. Taking this inevitable "partiality" of into account, it is particularly noteworthy to consider on what basis-that is, how and why - the objectifications are made. It is, likewise, appropriate to ponder whether the objectifications are a part of our usual and thus "normal" environmental relationship or a deviation from it. This is a crucial question, even though certain prevailing theoretical conceptions and ontological assumptions in the history of Western philosophy have admittedly favored the object-based model of environment and spatially located places (Casey 1997).

For example, though Relph founds his analysis of place, in part, on the Heideggerian account of being-in-the-world as the general human condition, he still seems to operate more or less in the field of subject- and consciousnessbased phenomenology, thus implicitly relying on the primacy of the object-based conception of place. This is 
especially the case as, despite the occasional references to the practical and existential dimensions of place, the comprehension of our constant and continuous embeddedness in the "worldhood" of world as a decisive feature of our relationship to places remains rather thin and ambiguous in Relph's account. This is most clearly manifest in the manner he examines places as backgrounds or contexts: while the places' function as backgrounds or contexts is indeed acknowledged, the "backgroundness" and "contextness" themselves as characteristic place-attributes are largely ignored.

What is most important, however, is the fact that there is no clear prioritization of one mode of places' being over the other, which might be a rather problematic and controversial situation from the Heideggerian point of view. As stated earlier, Heidegger-inspired accounts of placedness as the human condition understand places essentially as contexts of human existence and experience. Though it might not make sense to try arranging the different modes of places' being chronologically—questions such as "which came first" remain unanswered-the place-as-context mode still has a certain ontological priority. Human existence as being-inthe-world always "actualizes" as being-in-a-place (being in a place-as-context, to be exact), whereas objectified places emerge merely as "theoretically" formed abstractions and thus as within-the-world phenomena - that is, as phenomena that occur in a world that has already opened itself to us, as a contextual place.

Summarizing the remarks made thus far: the source of problems in Relph's account of places (and in a significant part of the academic tradition of place-research for that matter) is that he ends up treating places either as objects or as contexts rather equally—or, perhaps, even too equally. The fundamental reason for this kind of detrimental ambiguity in his treatment is a failure to recognize the ontological difference between places as ontic phenomena and places as ontological structures (see, e.g. Malpas 2006, p. 32) - that is, the difference between places encountered within the (life) world and places constitutive of the (life)world.

For Relph, the "contextual interpretation" of place means, above all, such configuration or composition of various environmental elements (including physical, social and symbolic dimensions; see e.g. Relph 2016, pp. 46-49) that form a basis for human activities and that currently are not in the focus of our consciousness, though in principle they could be. This kind of context seems to consist of specific "embedded objects"- that is, a diversity of objectual entities that, due to their embeddedness in the habitual routines of everyday life, are usually not visible to us-that belong to the sphere of unreflected ontic ${ }^{2}$. As such, Relph's conception

\footnotetext{
2 Special thanks go to Professor Raine Mäntysalo for this illustrative expression.
}

of places as contexts operates primarily on the ontic level, whereas the ontological dimension-though not altogether ignored-remains ambiguous and unexplicated.

The point here is that the singular concept of place cannot, or at least should not, be used to refer to these separate meanings without a major risk of confusion; to be sure, this is the very distinction that the proposed concepts of "place-as-object" and "place-as-context" underline. Relph's conceptual confusion eventually arises from the fact that he does not separate the intentionality of consciousness and the fundamental "in-order-to" reference structure of all human existence clearly enough: places-as-objects belong to the sphere of intentional consciousness, whereas placesas-contexts have to do with equipmental environments and the related existential intentionality.

\section{Objectified and Contextual Aesthetics}

In a similar way that the conception of place has for long been bound to an object-based mode of thinking, the mainstream tradition of Western philosophy has also interpreted "aesthetics" in an overly objectifying manner. To be more exact, the possible approaches to aesthetics have carried with them the burden of the subject-object dichotomy, according to which the meaning of aesthetics has been reducible either to the subjective side of aesthetic activities (e.g. pleasure, emotions, self-expression, different aesthetic attitudes), or to the object-related issues (e.g. inherent aesthetic values and meanings, the self-sufficiency of artworks). Indeed, as Heidegger (2002a, p. 66) has stated, there is a "necessary interplay between subjectivism and objectivism", and the comprehensive objectification of reality always involves a certain conception of human existence as a subject-that is, as a self-sufficient being that essentially serves as a basis for its own being.

With regard to the environment, the object-based interpretation of aesthetics has led to a rather undisputed objectification of various environments and an emphasis on the values inherent in either natural or artefactual "environmental objects". On the one hand, natural environments have been detached and isolated from human environments as some kind of museum-like reserves, where the inherent values of pure and pristine nature can be treasured. On the other hand, human environments have been conceived either as a collection of architectural pieces that exist as independent and solid, sculpture-like artworks, or as abstract forms and patterns of constructed entities (buildings, roads, parks, etc.) that are best viewed from an aerial perspective. Additionally, certain favorable natural and semi-natural environments have been reduced to scenic views-that is, picturesque 
landscapes that should be contemplated from a distance in order to achieve an aesthetic experience. ${ }^{3}$

The meaning of aesthetics can, however, be viewed from a very different perspective, questioning the relevance and sufficiency of objectual approach. In particular, Heidegger's essay "The Origin of the Work of Art" (originally published in 1935-1936) can be seen as a major-though not in any way unproblematic - contribution on the path towards a nonobject-based account of aesthetics. Despite the undisputed merits of the Heideggerian view, there are still remarkable issues present that stem, in part, from the fact that Heidegger does not separate the questions of aesthetics from those of art; for him, the philosophy of aesthetics is primarily a theory of art.

One way of summarizing the general significance of Heidegger's essay is that in a very concrete and illustrative manner it shows the constraints and the insufficiency of objectbased thinking. By revealing the essence of artworks as something that can be encountered within the world but that simultaneously has do to with the constitution of that very world, Heidegger does not necessarily succeed overly well in formulating an adequate and coherent theory about the issue, but instead he shows the impossibility of such a theory within the present object-oriented conceptual framework. In the following quotation, Heidegger (2002a, pp. 20-21) describes the complex relation between a Greek temple and the ancient Greek world:

A building, a Greek temple, portrays nothing. It simply stands there in the middle of the rocky, fissured valley. [...] The temple and its precinct do not, however, float off into the indefinite. It is the temple work that first structures and simultaneously gathers around itself the unity of those paths and relations in which birth and death, disaster and blessing, victory and disgrace, endurance and decline acquire for the human being the shape of its destiny. The all-governing expanse of these open relations is the world of this historical people.

Despite an explicit focus on art and the artwork, Heidegger implicitly provides the foundation for a novel approach to aesthetics more broadly: leaving aside the "artworkness" of the Greek temple (its "work-being"), one can conceive the temple as a more general aesthetic phenomenon, whose way of being (its "essence") is not bound to the realm of art and thus does not have to be "explained" accordingly. Instead of treating the temple as an object of art or architecture, or as an object of any kind, it can be seen as an aesthetic event that takes place in and gathers the ancient Greek world, simultaneously shaping the limits-the

\footnotetext{
3 See e.g. Berleant and Carlson $(2004,2007)$ for a more detailed discussion about the history of environmental aesthetics.
}

hermeneutical horizon - of the very same world. As an event, the temple is an essential part of the Greek world's "being" and evolution as a historical entity-its "worlding" as Heidegger (2002a, p. 23) puts it.

In order to address the interconnections between the event-like nature of an aesthetic entity (such as the Greek temple) and the ontic-ontological "dual identity" of places, it is necessary to examine the relation between experienced environmental objects and their experiential background in more detail. In a somewhat different context (in the essay "Building Dwelling Thinking" that is based on a lecture originally presented in 1951), Heidegger speaks of (environmental) "things" that due to their specific "thingness" open up the environing place- the place that both serves as the experiential background for the "things" themselves, and that they essentially are part of.

The central idea here is that the (contextual) place itself does not exist beforehand, so that the "thing" could merely enter it, but the "thing's" way of being is such that it gives rise to the place. Heidegger (1993, pp. 355-356, translation altered $^{4}$ ) uses an old bridge (located in Heidelberg) as an example of such a "thing":

The place is not already there before the bridge is. Before the bridge stands, there are of course many spots along the stream that can be occupied by something. One of them proves to be a place, and does so because of the bridge. Thus the bridge does not first come to a place to stand in it; rather, a place comes into existence only by virtue of the bridge.

Though Heidegger neither explicitly regards the bridge as an artwork nor addresses its broader aesthetic relevance, such a description of the bridge's place-opening quality bears a notable resemblance to his analysis of the Greek temple. Above all, the bridge and the temple both seem to have a dual identity as ontic and ontological phenomena: they both are encountered as entities within the lifeworld, while simultaneously having a role in the constitution of it. The "essence" of the bridge and the temple cannot thus be completely grasped from the sphere of mere everyday dealings, since they both have to do with the structuring of the everyday in question - albeit the bridge apparently operates in a smaller scale, and probably is of lesser significance concerning the overall constitution of a particular lifeworld.

From the experiential point of view this means that the bridge and the temple can indeed be experienced - they can serve as objects of experience-and they can have functions

\footnotetext{
4 The concept "locale" has been replaced with "place". In the German original version (Heidegger 2000, p. 156) the concept is "Ort", which is used to refer to place in the ontologically significant contextual sense-that is, not as a mere location or position of an ontic entity (Malpas 2006, pp. 30-32).
} 
with straightforward experiential implications; for example, the bridge can be used to cross the stream, and it plays a significant part in the local landscape. In addition to this, they also have functions that are not "experienceable" as such - having to do with the question of exactly what enters the sphere of experience, and how, in the course of our everyday dealings. For example, according to Heidegger (1993, p. 354), the old bridge "lets the stream run its course and at the same time grants mortals their way, so that they may come and go from shore to shore; [...] the bridge initiates the lingering and hastening ways of men to and fro, so that they may get to other banks and in the end, as mortals, to the other side." The bridge in question thus brings forth the stream as a freely running stream, the humans as mortals with their daily tasks and chores, and the relation between the bridge and the humans as such that the stream is let to run its course as the humans are busy with their mundane dealings and concerns.

Not every bridge brings forth the realities of a particular lifeworld in a similar way-the bridges in general do not have the same "aesthetic functions", even though their "equipmental functions" may be by and large equal. The "essence" of a bridge as a piece of functioning equipmental entity is that it grants a safe passage cross the stream, or whatever the obstacle to overcome may be, thus contributing essentially to the smoothness and the continuity of a specific life-form; the "essence" of a bridge as an aesthetic entity, in turn, is that it gives understandable experiential shape to the life-form in question, bringing forth the bridge $a$ s the particular bridge that eventually is of crucial importance for the smoothness and the continuity of the life-form specific mundane activities.

It must be stressed that Heidegger himself does not explicitly regard the described aesthetic functions of a "bridge-thing" as specifically aesthetic; for him, aesthetics pertains to the sphere of art and, to be sure, Heidegger uses the term "aesthetic" very scarcely and doubtfully. In this sense, what we have here is an "unorthodox interpretation" of Heideggerian thinking, but such liberality may be helpful in conceiving the experientially opaque amalgamation of equipmentality and aesthetics. More profound understanding of such "equipmental aesthetics" has particular relevance concerning environmental and urban aesthetics, where the more traditional, art-theory inspired object-based philosophy of aesthetics has very limited applicability. In the urban everyday, aesthetics is not something that is separate and disconnected from the "real life" but essentially embedded in it, playing an active part in the constantly ongoing process of defining and redefining what is valuable, meaningful, and thus desirable - and what is not.

As it has become clear, bridges and other environmental entities typically involve both equipmental and aesthetic values and meanings: in general, these are overlapping and not exclusive qualities, though some particular entities may (at a certain time) serve primarily either equipmental or aesthetic functions. For example, the old bridge in Heidelberg has previously had practical value as a crossover, and aesthetic value as a gatherer of the local world; nowadays, if the particular bridge still happens to stand in its place, it may have lesser practical value and more aesthetic value-reminding us of another kind of life-form, though perhaps in an overly nostalgic and romanticizing way. The point is that neither of these attributes exhausts the "essence" of the bridge completely, and it can, and sometimes indeed should, be assessed from both these perspectives.

We may now return to the question concerning the interconnections between the aesthetic event and ontic-ontological places. According to Heidegger (1993, p. 357), the old bridge in Heidelberg not merely stands in a place, nor opens up a place, but it is a place. What is most important is that it is a place in both ontic and ontological sense: it can be experienced as an (ontic) object, but it also serves as an (ontological) context for experience. The ontologicality of the "bridge-place" stems primarily from the fact that it grants the local people their passage cross the stream: as an equipmental environmental entity, the bridge affords a diverse set of uses and activities, playing a remarkable part in the realization of various existential intentionalities. In addition to this, as an aesthetic environmental entity, the bridge essentially reveals its equipmentality, and the afforded uses and activities as such. The old bridge is thus a contextual place of a special kind-not merely providing a specific life-form with a material basis for realizing the existential intentionalities, but also bringing forth the existential intentionalities and their material basis as such. This place-based, event-like disclosure of the sosio-material structuration of a life-form is what the aesthetics of a contextual place is all about.

\section{The Aesthetics of Urban Places Reconsidered}

Taking into account the historical burden of object-based thinking in Western philosophy, it is not at all surprising that there have also been major conceptual limitations regarding the aesthetics of place. To be sure, the aesthetics of place has suffered from a sort of "double objectification": it is not only aesthetics, but also places that have typically been reduced to objects of consciousness and their characteristic features. However, the aesthetics of urban places is not merely, or even primarily, about the presence of specific aesthetic objects that represent different aesthetic valuessuch as various architectural masterpieces and other iconic symbols in the built form, manifesting economic grandeur and sophisticated cultural identity. Rather it has to do with 
the material and immaterial contexts that continuously and inevitably frame people's everyday life.

Furthermore, it can be argued that the "everydayness" of urban contexts is itself largely aesthetic phenomenon, so that the self-evident and unquestionable givenness or normalcy of the urban places is aesthetically constructed. What is conceived as the "normal way" of being and acting in the urban places has to do with the life-form related conceptions of properness and desirability - which, in turn, are conveyed to daily urban experience via aesthetic values and meanings. In general, the uses and actions that a particular place affords are manifold and virtually innumerable, and it is precisely the aesthetics that makes us conceive a place as the place for something - that is, as the place that can be used in-order-to (do or gain) something. The aesthetics of urban places is thus about defining and redefining the urban lifeworld, according to some particular conception or ideal of urban life; as such it is of exceptional political and ideological relevance.

Making the place-based environmental functionalities conceivable is essentially connected to conceptualizing and thus objectifying environment. By shifting the focus from already objectified places to the process of objectifying them, and to the role that aesthetics has within this process, it becomes possible to emphasize the contingency of place-based environmental objectifications. On the basis of this, it might even be argued that deliberately highlighting the object-like and supposedly static aesthetic values and meanings of urban places is a rather effective method of fading out and understating the questions of ideology and power that are always implicitly inherent in the discourses and policies of place and place-making.

Despite the reductive nature of all objectificationsincluding the attempts to make any statements about the character or identity of a place-it is precisely these kinds of simplified theoretical abstractions that we have to deal with, if we wish to have any kind of deliberate and intentional control over our urban habitat. This being the case, the most central questions concern the particular ways and situations in which objectifications occur, as well as the experiential and non-conceptual basis from which a certain environmental object eventually arises as a manageable and manipulable object.

Established urban design practices surely constitute one prominent way of objectifying places, but it is very important to ask what, exactly, is the relation between the designer's and the locals' view of the place. Judging from a critical design-theory point of view, it is not enough to engage the place-based communities, focus groups and individuals by merely including their local narratives of place to the placemaking design machinery (cf. Julier 2000, pp. 119-125), for much of the essence of a place-and the related place identity-is non-conceptual and experiential in such a way that it cannot be captured by mere abstract concept-level depictions of place. Thus what is central to an "authentic place", for instance, is the level of everyday use and action (both shared and individual) - that is, the concrete sociomaterial realities of a place that are inherently embedded in the interpretative experience of the inhabitants, and the other users of that place. Place identity and the related authenticity thus comprise of a way of seeing the world or, to be more exact, a way of being in the world-not a set of commodified "identity symbols" that can be easily attached to an already existent place.

The concrete outcomes of the various place-making policies and practices inevitably and indisputably do have effects also on the level of such experiential place identity, but the underlying mechanisms are likely to be much more complicated than the "place-makers" seem to think. It is, to be sure, possible to alter and enhance existent places-and even to create flourishing new ones-but in order to gain success in such an endeavor one has to take seriously the non-conceptual level values and meanings that give form to human being's "placed existence". The aesthetics of place, in turn, is likely to have central role in a successful place-making project, for it is the aesthetic dimension that is of crucial importance in the initial arrangement - and the potential re-arrangements - of people's multidimensional and dynamic relation to their environment. It is through the "aesthetic means" that people experience their home as their personal place for living, the nearby park as a shared extension of their personal place, and the city as a multiplicity of places, manifesting the diverse values of its heterogeneous inhabitants.

Acknowledgements I wish to thank Arto Haapala and Raine Mäntysalo for all the in-depth discussions, and for their insightful views on the subject matter. I also wish to thank Michael Nagenborg for an eyeopening literature recommendation. Finally, I wish to thank the three anonymous reviewers for their comments on this paper.

\section{Compliance with Ethical Standards}

Conflict of interest The author declares that he has no conflict of interest.

Research Involving Human and Animal Rights This article does not contain any studies with human participants or animals performed by the author.

Open Access This article is distributed under the terms of the Creative Commons Attribution 4.0 International License (http://creativeco mmons.org/licenses/by/4.0/), which permits unrestricted use, distribution, and reproduction in any medium, provided you give appropriate credit to the original author(s) and the source, provide a link to the Creative Commons license, and indicate if changes were made. 


\section{References}

Berleant A, Carlson A (2004) Introduction in: the aesthetics of natural environments. Broadview Press, Peterborough

Berleant A, Carlson A (2007) Introduction in: the aesthetics of human environments. Broadview Press, Peterborough

Casey ES (1997) The fate of place: a philosophical history. University of California Press, Berkeley \& Los Angeles

Dovey K (1999) Framing places: mediating power in built form. Routledge, London

Dovey K (2016) Place as multiplicity. In: Freestone R, Liu E (eds) Place and placelessness revisited. Routledge, New York

Haapala A (2005) On the aesthetics of everyday: familiarity, strangeness, and the meaning of place. In: Light A, Smith JM (eds) The aesthetics of everyday life. Columbia University Press, New York

Haapala A (2017) The everyday, building, and architecture: reflections on the ethos and beauty of our built surroundings. Cloud-cuckooland. Int J Arch Theory 22:169-182

Heidegger M (1978) Being and time. 4th edn (trans: Macquarrie J, Robinson E). Basil Blackwell, Oxford

Heidegger M (1982) The basic problems of phenomenology. Indiana University Press, Bloomington

Heidegger M (1993) Building dwelling thinking. In: Krell DF (ed) Basic writings. HarperCollins, New York

Heidegger M (2000) Bauen wohnen denken. In: Gesamtausgabe Band 7: Vorträge und Aufsätze. Vittorio Klostermann, Frankfurt am Main

Heidegger M (2002a) The age of the world picture. In: Young J, Haynes K (eds) Off the beaten track. Cambridge University Press, Cambridge
Heidegger M (2002b) The origin of the work of art. In: Young J, Haynes K (eds) Off the beaten track. Cambridge University Press, Cambridge

Ihde D (1979) Technics and praxis. Reidel Publishing, Dordrecht

Julier G (2000) The culture of design. Sage, London

Knox PL (2005) Creating ordinary places: slow cities in a fast world. J Urban Desn 1:1-11

Kovács Z, Musterd S (2013) The importance of places and place branding. In: Musterd S, Kovács Z (eds) Place-making and policies for competitive cities. Wiley Blackwell, Hoboken

Lister N-M (2012) Map-making as place-making: building social capital for urban sustainability. In: Robinson P, Dale A, Dushenko WT (eds) Urban sustainability: reconnecting space and place. University of Toronto Press, Toronto

Malpas J (1999) Place and experience: a philosophical topography. Cambridge University Press, Cambridge

Malpas J (2006) Heidegger's topology: being, place, world. MIT Press, Cambridge

Malpas J (2012) Heidegger and the thinking of place: explorations in the topology of being. MIT Press, Cambridge

Olivier A (2017) Understanding place. In: Janz BB (ed) Place, space and hermeneutics. Springer, Cham

Palermo PC, Ponzini D (2015) Place-making and urban development: new challenges for contemporary planning and design. Routledge, New York

Relph E (2016) Place and placelessness, 4th edn. Sage, London

Verbeek P-P (2005) What thing do. Philosophical reflections on technology, agency, and design. Pennsylvania State University Press, Pennsylvania 